\title{
Application of Artificial Neural Networks for Short term Price Forecasting in Deregulated Power Market
}

\author{
Kalyanasundaram Vakesan ${ }^{1}$ and Vijayakumar Krishnamoorthy ${ }^{2}$ \\ ${ }^{1}$ Research scholar, ${ }^{2}$ Professor \\ ${ }^{1,2}$ Department of Electrical and Electronics Engineering, SRM Institute of Science \\ and Technology, Chennai \\ ${ }^{1}$ kalyan.srm@gmail.com, ${ }^{2}$ kvijay_srm@redifmail.com
}

\begin{abstract}
The power value assurance is the long haul prepares which relies on cost of creation, load request, accessibility of era, unit duty and the limitations on the transmission network. The scope of this paper is to maximize the social welfare for the society. The market clearing price depends on the number of the generators and customer needs. In this paper, power frameworks advancement at anticipating Market Costs in deregulated power markets using ANN is executed. In the modern energy exchanging situation, deciding the market clearing value plays a fundamental role. The required solution can be obtained by collecting Marginal cost price from different generating stations and also from the load centers.
\end{abstract}

Keywords: Marginal cost price (MCP), Locational Marginal Pricing (LMP), Marginal Absolute Percentage Error (MAPE), Artificial Neural Network (ANN)

\section{Introduction}

Power Supply Industry across the world, is rebuilding for more advantageous use of assets and giving quality administration and decision to the purchaser at economical costs. Rebuilding of the power business reabolishing the restraining infrastructure in the era and exchanging parts, along these lines, presenting rivalry at different levels wherever it is possible[1-2]. Power segment rebuilding in Power Market, which is prominently known as deregulation, is probably going to draw private venture, to build productivity, advance specialized development and enhance consumer loyalty as various gatherings rival each other to win their piece of the pie and stay in business [3-5]. Aggressive power markets are mind boggling frameworks with numerous members who purchase and offer electricity. When the makers and buyers of electrical vitality yearning to deliver and devour in sums that would make the transmission framework work at the rated or past at least one exchange limits, then the framework is known to be congested[6-8].

By and by, there are two estimating strategies that are being utilized as a part of an aggressive vitality market to represent congestion: the uniform valuing technique and the non-uniform evaluating strategy. In the main technique, all generators are paid a similar value independent of their individual offers in light of the offer of the negligible producing unit that would be dispatched without congestion. This sort of an offer is well to say as the Market Clearing Price (MCP) [9-11]. Vitality costs would not represent congestion and extra expenses because of congestion will be passed on to all heaps in extent to their utilization (the U.K. pool and NORD pool is a case of this sort). In the second technique, or at times called Locational Marginal Pricing (LMP), every generator is paid a cost in view of the negligible cost of allocation, by an augmentation of load at its area. The LMP at a transport is characterized as the base minor cost of providing the

Received (August 20, 2017), Review Result (December 14, 2017), Accepted (December 24, 2017) 
following augmentation of electric vitality at the transport without infringement of any transmission limits. These minimal costs would be founded on generator offers, the framework administrator dispatch, and any transmission constraints [12-13].

In this paper, in order to compute the Locational marginal price, to obtain more accurate results the load forecasting and price forecasting results of the Artificial Neural Networks considered.

\section{Locational Marginal Pricing}

In an unconstrained transmission system, generators are dispatched in view of their offering costs and the LMP is the same at any hub (transport) in the framework and is equivalent to the MCP. At the point when there are transmission requirements, the framework era dispatch would be unique in relation to the slightest offering value dispatch and, in this manner, LMPs can change all through the transmission framework. Changes in framework working conditions and in framework parameters could likewise affect LMPs.

Locational Marginal Price (LMP) is equal to the sum of the Generator's Marginal cost, Congestion cost of Transmission system, and Marginal Loss's cost. The LMP value is the same as MCP if there is no congestion in the system. The marginal cost of each bus is the LMP.

\subsection{Objective of this Model}

This work focuses on calculating, Market Clearing Price value in the IEEE 30 bus system under various standard conditions. Security checks can be performed after the market clearing and MCP calculations done in the real power market. The results obtained from the power flow are used for forecasting of load and also the MCP forecasting has been done on the ISO NEW ENGLAND and NORD pool system.

\section{Artificial Neural Network (ANN)}

Neural systems are basically non-linear circuits and basically utilized for the non-linear curve fitting. The yields of a counter fit neural system are some straight or non-linear numerical capacity of its data sources. ANN is normally displayed with a large number or a great many straight forward handling units, associated in parallel and nourishing forward in a few layers. Due to the quick and cheap pcs accessibility, the enthusiasm for ANN's has bloomed in the current computerized world. The primary thought for the improvement of the ANN is to make the pcs to perform work, of what a human personality can perform. Stack forecasting should be possible by developing a three-layer, feed-forward neural network. It contains an input layer, one hidden layer and an output layer. Flag framework is permitted just from the info layer to the hidden layer and from the hidden layer to the output layer, which is shown in Figure 1.

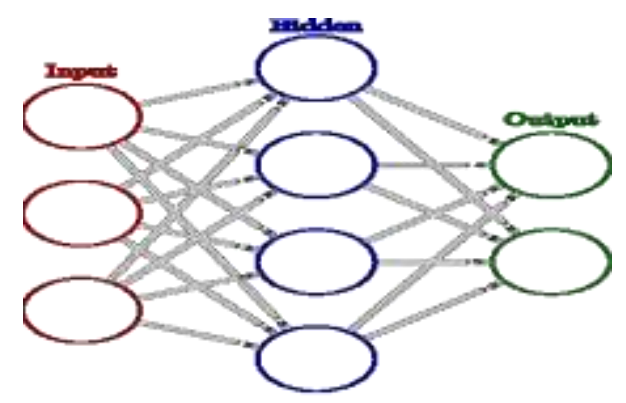

Figure 1. Structure of ANN 


\subsection{Short -term Load Forecasting using ANN}

The factors such as humidity, wind speed and temperature influences the accuracy of load forecasting. Among of the listed factors, temperature plays a vital role. The relation between Load and temperature is given by

$$
L=\sum_{i=1}^{N} a_{i}\left\{u\left(T-T_{i 1}\right)-u\left(T-T_{i 2}\right\}+C\right.
$$

Where $\mathrm{U}(\mathrm{T})=\{1$ if $\mathrm{T}>=0 ; 0$ other wise $\}$

$\mathrm{a}_{\mathrm{i}}, \mathrm{T}_{\mathrm{i} 1}, \mathrm{~T}_{\mathrm{i} 2}$ are constant, $\mathrm{T}_{\mathrm{i} 1}>\mathrm{T}_{\mathrm{i} 2}$ for all $\mathrm{i}$

The input to the ANN is temperature, humidity, actual load and previous day load for 24 Hours. The results of short term load forecasting are shown in below.

Table 1. Load Forecasting

\begin{tabular}{llllll}
\hline \hline Time (Hours) & $\begin{array}{l}\text { Actual } \\
\text { Load } \\
(\mathrm{MW})\end{array}$ & $\begin{array}{l}\text { Forecasted } \\
\text { Load (MW) }\end{array}$ & Time (Hours) & $\begin{array}{l}\text { Actual } \\
\text { Load } \\
(\mathrm{MW})\end{array}$ & $\begin{array}{l}\text { Forecasted } \\
\text { Load (MW) }\end{array}$ \\
\hline \hline 0:00-1:00 & 150 & 149.9848 & $12: 00-13: 00$ & 260 & 259.9555 \\
1:00-2:00 & 140 & 139.6696 & $13: 00-14: 00$ & 260 & 260.3905 \\
2:00-3:00 & 120 & 119.8711 & $14: 00-15: 00$ & 255 & 254.8663 \\
3:00-4:00 & 135 & 134.9805 & $15: 00-16: 00$ & 270 & 269.9825 \\
4:00-5:00 & 150 & 142.9196 & $16: 00-17: 00$ & 270 & 269.9537 \\
5:00-6:00 & 170 & 180.5961 & $17: 00-18: 00$ & 255 & 254.9281 \\
6:00-7:00 & 180 & 179.9593 & $18: 00-19: 00$ & 240 & 239.9407 \\
7:00-8:00 & 210 & 220.5311 & $19: 00-20: 00$ & 230 & 230.0901 \\
8:00-9:00 & 220 & 241.9615 & $20: 00-21: 00$ & 220 & 206.4748 \\
9:00-10:00 & 240 & 239.8195 & $21: 00-22: 00$ & 180 & 179.9888 \\
10:00-11:00 & 250 & 249.8696 & $22: 00-23: 00$ & 150 & 150.0872 \\
11:00-12:00 & 255 & 254.8959 & $23: 00-0: 00$ & 130 & 143.0395 \\
\hline
\end{tabular}

\subsection{Short-term Load Forecasting (for 24 hours) using ANN}

Table 2 summarizes the variation of the load for each hour with the variations in the average bus marginal cost and the total cost for the corresponding load variations. For practical real time power system, these load variations are made with reference to the daily load curve.

The input data to ANN-network will be the present hourly load data for 24-hrs, previous day load, temperature and humidity for each hour of the previous day. The target data to ANN will be the hourly load data of 24-hrs. These data's are taken from the standard IEEE papers as shown in Table 2. 
Table 2. Actual Average Marginal cost

\begin{tabular}{llll}
\hline $\begin{array}{l}\text { Time } \\
\text { (in Hours) }\end{array}$ & $\begin{array}{l}\text { Load } \\
\text { (in MW) }\end{array}$ & $\begin{array}{l}\text { Average Bus Marginal } \\
\text { cost (in Rs/MWh) }\end{array}$ & $\begin{array}{l}\text { Total Cost*10^3 } \\
\text { (in Rs/MWh) }\end{array}$ \\
\hline \hline 0:00-1:00 & 150 & 81.72 & 20.7001 \\
1:00-2:00 & 140 & 72.40 & 19.930 \\
2:00-3:00 & 120 & 37.85 & 18.755 \\
3:00-4:00 & 135 & 66.44 & 19.565 \\
4:00-5:00 & 150 & 81.72 & 20.700 \\
5:00-6:00 & 170 & 93.60 & 22.507 \\
6:00-7:00 & 180 & 96.55 & 23.454 \\
7:00-8:00 & 210 & 144.97 & 27.340 \\
8:00-9:00 & 220 & 159.05 & 28.912 \\
9:00-10:00 & 240 & 181.54 & 32.527 \\
10:00-11:00 & 250 & 214.72 & 34.510 \\
11:00-12:00 & 255 & 224.49 & 35.596 \\
12:00-13:00 & 260 & 224.88 & 36.698 \\
13:00-14:00 & 260 & 224.88 & 36.698 \\
14:00-15:00 & 255 & 224.49 & 35.596 \\
15:00-16:00 & 270 & 268.99 & 39.013 \\
16:00-17:00 & 270 & 268.99 & 39.013 \\
17:00-18:00 & 255 & 224.49 & 35.596 \\
18:00-19:00 & 240 & 181.54 & 32.527 \\
19:00-20:00 & 230 & 181.54 & 30.699 \\
20:00-21:00 & 220 & 159.05 & 28.912 \\
21:00-22:00 & 180 & 96.55 & 23.454 \\
22:00-23:00 & 150 & 81.71 & 20.712 \\
23:00-0:00 & 130 & 67.68 & 19.340 \\
\hline & & &
\end{tabular}

\subsection{Comparison of Actual (Target) Load with the Forecasted Load}

The forecasted load on the system using ANN can be compared with the actual load of the system for the analysis of the MAPE.

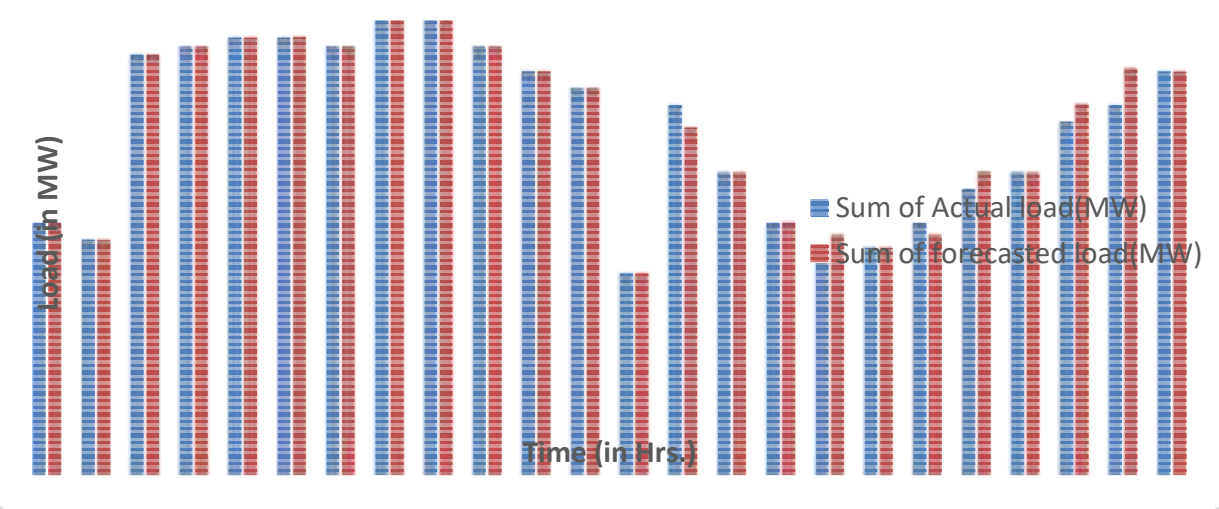

Figure 4. Plot Showing Actual and Forecasted Load

And by this analysis the MAPE can be determined for a forecasted load of 24-Hrs, by using

$$
\operatorname{MAPE}(\%)=\frac{1}{N} \sum_{i=1}^{N} \frac{\left|P_{A}^{i}-P_{F}^{i}\right|}{P_{A}^{i}} \mathrm{X} 100
$$


Here the MAPE (\%) obtained is 3.276 .

\section{Locational Marginal Price forecasting using ANN}

The ANN technique is relatively simple to actualize. In any case, it neglects to catch verifiable varieties (e.g., congestion and possibility).The inputs layer of the Neural Network are the time (day of the week and hour of the day), load factor (framework load and transport load), and line data (line status, line constraints). The output layer refers to individual transport costs. The number of neurons in the hidden layer is normally equal to the number of neurons in its input and output layers.

The factors considered for electricity price forecasting is the sum of the following:

Time Factor (Hour of the day, day of a week, year, month and special days), Reserve Factor( Historical and forecasted reserve, Price Factor ( Historical price ) and Load data ( Historical and forecasted loads).The load fluctuations will impact the price.

Price forecasting :

$$
\operatorname{Price}(d, h)=\frac{\operatorname{Load}(d, h) * \operatorname{Price}(d-1, h)}{\operatorname{Load}(d-1, h)}
$$

Where Load $(\mathrm{d}, \mathrm{h})=$ Forecasted load

Load $(\mathrm{d}-1, \mathrm{~h})=$ Actual load for the hour $\mathrm{h}$ of the previous day $\mathrm{d}-1$

Price $(\mathrm{d}-1, \mathrm{~h})=$ Actual price for the hour $\mathrm{h}$ of the previous day $\mathrm{d}-1$

\subsection{Simulation Model of ANN for Price Forecasting}

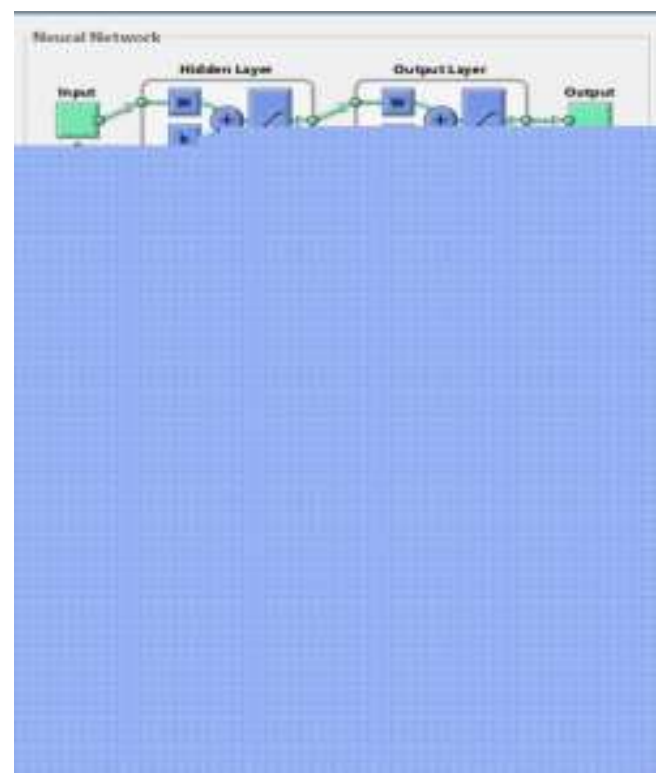

\section{Figure 5. Simulation Diagram of ANN for Price Forecasting of a Day}

The simulation is carried out by using Levenberg-Marquardt Algorithm by using the Tan sigmoidal function and Back-Propagation technique.

\subsection{Performance Plot of ANN of Price Forecasting for 24Hrs}

The performance plot determines the best performance of ANN with the help of input data, training data and testing for its best validation. The comparison between the actual $\mathrm{MC}$ and the forecasted $\mathrm{MC}$ for $24 \mathrm{Hrs}$ can be made as follows by using the ANN results. 


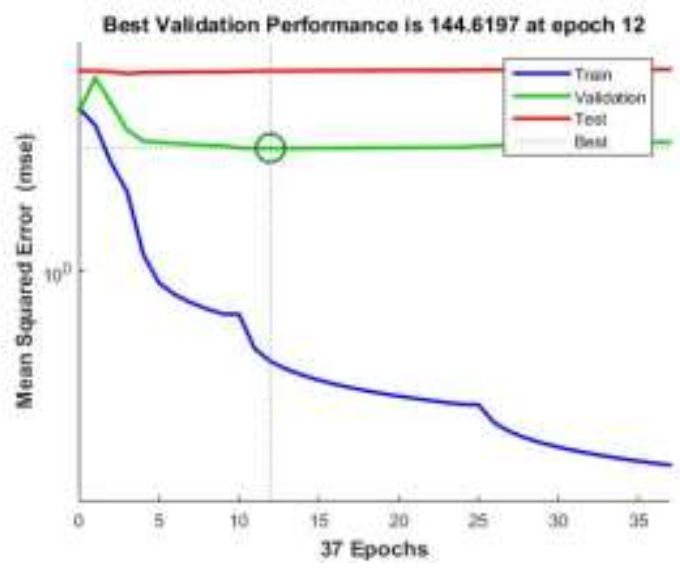

Figure 6. Performance Plot of ANN for 24Hrs of Price Forecasting

Table 2. Actual Avg. MCP (Vs.) Forecasted Avg. MCP

\begin{tabular}{llllll}
\hline $\begin{array}{l}\text { Time } \\
\text { (Hrs) }\end{array}$ & $\begin{array}{l}\text { Actual } \\
\text { MCP } \\
\text { (RS/MWh) }\end{array}$ & $\begin{array}{l}\text { Avg.Forecasted } \\
\text { MCP } \\
\text { (RS/MWh) }\end{array}$ & $\begin{array}{l}\text { Avg. Time } \\
\text { (Hrs.) }\end{array}$ & $\begin{array}{l}\text { Actual } \\
\text { MCP } \\
\text { (RS/MWh) }\end{array}$ & $\begin{array}{l}\text { Avg. Forecasted } \\
\text { Avg. MCP } \\
\text { (RS/MWh) }\end{array}$ \\
\hline \hline 0:00-1:00 & 81.72 & 68.83697504 & $12: 00-13: 00$ & 224.88 & 224.8526615 \\
1:00-2:00 & 72.4 & 72.3942592 & $13: 00-14: 00$ & 224.88 & 247.502419 \\
2:00-3:00 & 37.85 & 48.73291395 & $14: 00-15: 00$ & 224.49 & 224.4669833 \\
3:00-4:00 & 66.44 & 50.36999821 & $15: 00-16: 00$ & 268.99 & 268.769594 \\
4:00-5:00 & 81.72 & 62.12159037 & $16: 00-17: 00$ & 268.99 & 268.3996838 \\
5:00-6:00 & 93.6 & 93.58863293 & $17: 00-18: 00$ & 224.49 & 224.46206 \\
6:00-7:00 & 96.55 & 96.55983191 & $18: 00-19: 00$ & 181.54 & 181.5373573 \\
7:00-8:00 & 144.97 & 39.26019263 & $19: 00-20: 00$ & 181.54 & 181.459442 \\
8:00-9:00 & 159.05 & 159.0493608 & $20: 00-21: 00$ & 159.05 & 158.9773693 \\
9:00-10:00 & 181.54 & 181.569373 & $21: 00-22: 00$ & 96.55 & 96.52242844 \\
10:00-11:00 & 214.72 & 179.051367 & $22: 00-23: 00$ & 81.71 & 87.69528714 \\
11:00-12:00 & 224.49 & 224.4781663 & $23: 00-0: 00$ & 67.68 & 67.64677785 \\
\hline
\end{tabular}

\subsection{Calculation of MAPE for $24 \mathrm{Hrs}$}

$$
\operatorname{MAPE}(\%)=\frac{1}{N} \sum_{i=1}^{N} \frac{\left|P_{A}^{i}-P_{F}^{i}\right|}{P_{A}^{i}} \times 100
$$

Where $p_{A}$ and $p_{B}$ are the hourly actual and forecasted prices and " $\mathrm{N}$ " is the number of hours, and "i" is the hour index.The MAPE (\%) obtained is $6.27922 \%$

$$
\text { Average Price }=\frac{1}{N} \sum_{i=1}^{N} P_{A}^{i}
$$




\subsection{Bar graph of Forecasted Avg.MC for 24Hrs}

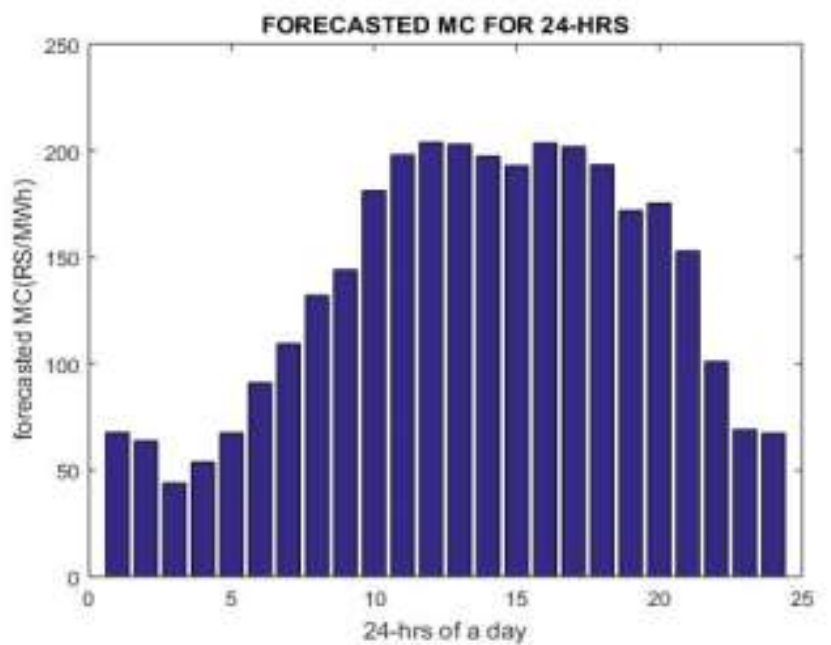

Figure 7. Bar Graph Representing Forecasted Average Marginal Cost

\subsection{Forecasting of MCP'S in the Nord Pool Power Market}

Here we are going to forecast the MCP'S for 24 hours of a week of NOV 2016 on SE systems of NORDPOOL.

In this type of Forecasting the Inputs to the ANN are: temperature of a day, MCP of the system in NOV 2016 and previous year NOV 2015 data of the first week, daily MCP'S of 24 hours of a week of NOV 2015 and NOV 2016 and weekly demand for 24 hours on the system.

The Target Data to the ANN will be the present 24 hours MCP data of first week of NOV. The simulation of ANN, Performance Plot and Forecasted data (output) are shown below:

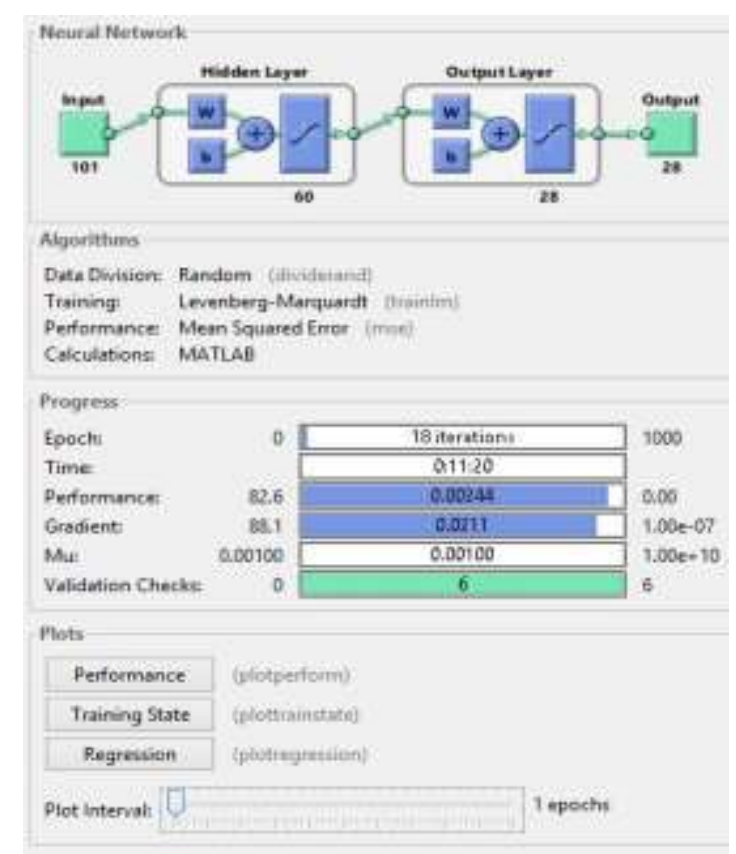

Figure 8. Simulation Diagram of ANN of NORDPOOL Market 


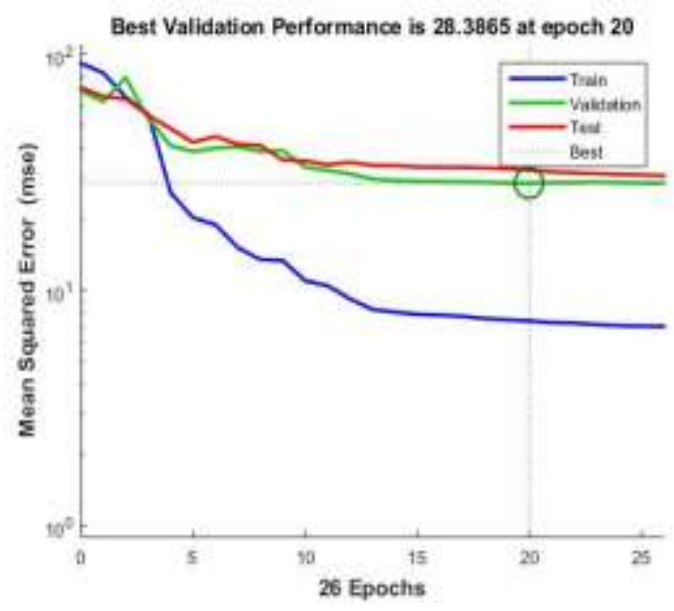

Figure 9. Performance Plot of NORDPOOL Market for a Day

Table 3. Actual Average MCP vs. Forecasted Average MCP

\begin{tabular}{lll}
\hline Time(Hrs.) & Actual & $\begin{array}{c}\text { Avg.Forecasted } \\
\text { MCP(EURO/MWh) MCP(EURO/MWh) }\end{array}$ \\
\hline \hline 0:00-1:00 & 33.23036939 & 34.42000 \\
1:00-2:00 & 33.19324674 & 33.68 \\
2:00-3:00 & 33.19505643 & 33.310 \\
3:00-4:00 & 33.21626914 & 33.01000 \\
4:00-5:00 & 33.12774082 & 33.540000 \\
5:00-6:00 & 33.07139372 & 34.920000 \\
6:00-7:00 & 33.01041552 & 40.1300 \\
7:00-8:00 & 42.12350517 & 42.0800000 \\
8:00-9:00 & 42.67159277 & 42.880000 \\
9:00-10:00 & 42.35298407 & 42.360000 \\
10:00-11:00 & 41.14249546 & 39.8900000 \\
11:00-12:00 & 39.99548216 & 39.930000 \\
12:00-13:00 & 39.48564466 & 40.85000 \\
13:00-14:00 & 40.07184009 & 40.1300000 \\
14:00-15:00 & 33.83437195 & 39.1900000 \\
15:00-16:00 & 36.91396687 & 39.640000 \\
16:00-17:00 & 40.81995077 & 40.720000 \\
17:00-18:00 & 44.3195624 & 44.6100000 \\
18:00-19:00 & 44.52207649 & 43.0600000 \\
19:00-20:00 & 33.26775399 & 39.35000 \\
20:00-21:00 & 33.0100882 & 37.150000 \\
21:00-22:00 & 33.01001287 & 36.5500000 \\
22:00-23:00 & 33.0122924 & 34.56000 \\
23:00-0:00 & 33.27080481 & 33.05000 \\
\hline & &
\end{tabular}


And the MAPE (\%) was calculated by comparing the forecasted MCP with actual MCP. If the error is small the accuracy of the forecasted MCP will be better values. The MAPE (\%) of NORDPOOL system for 24 hours is $1.267 \%$. Similarly, MCP's for remaining days of a week can be calculated.

\section{Conclusion}

This paper embodies a day ahead short term electrical load and price forecasting using ANN technique in ISO New England Market and in NORDPOOL Market. In ISO New England power market, the main drawback is the daily market price, in which the curves are extremely unpredictable. The simulation results are produced with accurate predictions even though the cases are unpredictable. The test results say that the electricity prices get affected mainly due to the variations in the power demand. The ANN model is used to determine the forecasted price for a day of 24 hours. The MAPE results obtained are $3.276 \%$ and $6.2792 \%$ for load forecasting and price forecasting respectively for a day of 24 hours. Whereas for the NORDPOOL Market MAPEis 1.267\% .The forecasted results obtained from the developed structure of ANN are very accurate with least error is achieved.

\section{References}

[1] H. Wang, C. E. Murillo-Sánchez, R. D. Zimmerman and R. J. Thomas, Fellow, "On Computational Issues of Market-Based Optimal Power Flow", IEEE Transactions on power Systems, vol. 22, no. 3, (2007), pp. $1185-1193$.

[2] B.B. Chakrabarti, C. Edwards, C. Callaghan and S. Ranatunga, "Alternative loss model for the New Zeland electricity market using SFT", Proceedings of the IEEE Power and Energy Soc.General Meeting, (2011).

[3] M. Shahidehpour and H. Yamin, "Market Operations in Electric Power Systems", forecasting, scheduling and risk management.

[4] A. Badri, Z. Ameli and A.M. Birjandi, "Application of Artificial Neural Networks and Fuzzy logic Methods for Short Term Load Forecasting”, Proceedings of Energy, vol. 14, (2012), pp. 1883-1888.

[5] W. Rosehart, "Optimal power flows incorporating network stability", Proceedings of the IEEE Power Engineering Society Winter Meeting, (2002), pp. 1100-1104.

[6] .Charytoniuk and M.S. Chen, "Very Short-Term Load Forecasting using Artificial Neural Networks", IEEE Trans. Power Syst., vol. 15, no. 1, (2000), pp.263-268.

[7] D. Kirschen, R. Allan and G. Strbac, "Contributions of individual generators to loads and flows", IEEE Transactions on Power Systems, vol. 12, no. 1, (1997), pp. 52-57.

[8] T. Yalcinoz and U. Eminoglu, "Short term and medium term power distribution load forecasting by neural networks", Energy Conversion. And Management, vol. 46, (2005), pp. 1393-1405.

[9] N. Kandil, R. Wamkeue, M. Saad and S. Georges, "An efficient approach for short term load forecasting using artificial neural networks", Elect. Power \& Energy Syst. vol. 28, no. 8, (2006), pp. 525-530.

[10] L. Chen, H. Suzuki, T. Wachi and Y. Shimura, "Components of nodal prices for electric powersystems", IEEETrans.PowerSyst.,vol.17,no.1, (2002), pp.41-49.

[11] T. Orfanogianni and G. Gross, "A general formulation for LMP evaluation", IEEE Trans.Power syst., vol.2, no.3, (2007), pp. 1163-1173.

[12] K. B. Sahay and M. M. Tripathi, "An analysis of short-term price forecasting of power market by using ANN”, IEEE Power India International Conference (PIICON), Delhi, (2014), pp. 1-6.

[13] S.C. Bhattacharyya and L.T. Thanh, "Short-term electric load forecasting using an artificial neural network: case of Northern Vietnam”, Int. J.Energy Res., vol. 28, (2004), pp. 463-472. 


\section{Authors}

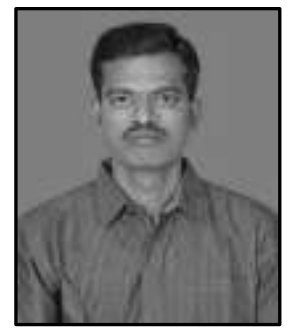

V Kalyanasundaram, he currently working as Assistant Professor in the EEE Department at SRM Institute of science and Technology, Chennai, India. He received M.E in Power systems from Annamalai University in the year 2005. He is currently pursuing his Ph.D degree at SRM Institute of science and Technology in the area of Locational Marginal price in Deregulated power market. His area of interest includes Power System Operation and Control, FACTS and Power System Protection.

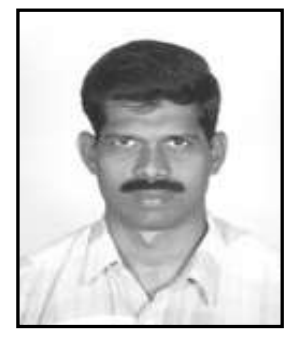

K Vijayakumar, he is currently working as Professor and Head in EEE Department at SRM Institute of science and Technology, Chennai, India. He received M.E in Power systems from Annamalai University in the year 1997.He has received his Ph.D degree in SRM Institute of science and Technology in the area of Deregulation systems.His area of research interests includes Computational Intelligence applications in Power Systems, FACTS and Power System Operation and Control 